Cultura Pop. Resignificaciones y celebraciones de la industria cultural en el siglo XXI Nancy Díaz Larrañaga

Question/Cuestión, Nro.70, Vol.3, diciembre 2021

ISSN: 1669-6581

URL de la Revista: https://perio.unlp.edu.ar/ojs/index.php/question/

IICom -FPyCS -UNLP

DOI: $\underline{\text { https//doi.org/10.24215/16696581e602 }}$

\title{
Cultura Pop
}

Resignificaciones y celebraciones de la industria cultural en el siglo XXI

\section{Pop Culture}

\section{Resignifications and celebrations of the cultural industry in the XXI century}

\section{Nancy Díaz Larrañaga}

Universidad Nacional de Quilmes- Facultad de Periodismo y Comunicación Social Universidad Nacional de La Plata

Argentina

nlarran@perio.unlp.edu.ar http://orcid.org/0000-0001- 9727-4718

\section{Resumen}

Pocos/as pueden detenerse sobre las prácticas cotidianas y repreguntarse sobre sus sentidos y densidad cultural como lo hacen Leonardo Murolo e Ignacio Del Pizzo en el libro "Cultura Pop. Resignificaciones y celebraciones de la industria cultural en el siglo XXI". Mezcla 
de familiaridad temática con espesor conceptual; mixtura de puro presente con nostalgia y pasado; ensamble de sujetos, apropiaciones, uso y tecnologías. Todo esto y mucho más nos ofrece el libro editado por Prometeo.

\section{Abstract}

Few / as can stop on the daily practices and cross-examine their senses and cultural density as Leonardo Murolo and Ignacio Del Pizzo do in the book "Pop Culture. Resignifications and celebrations of the cultural industry in the XXI century". Mix of thematic familiarity with conceptual thickness; mixture of pure present with nostalgia and past; assemblage of subjects, appropriations, use and technologies. All this and much more offers us the book edited by Prometeo.

\section{La invitación}

Cultura Pop: Resignificaciones y celebraciones de la industria cultural en el siglo XXI es una gran invitación. Una invitación de las que uno/a recibe con mucha alegría y expectativa y a la que no puede reusarse. Su arte gráfica nos provoca de entrada: nos llena de colores fluo e imágenes retro que ofician de cebo inmediato para tomar el libro y abrirlo. 


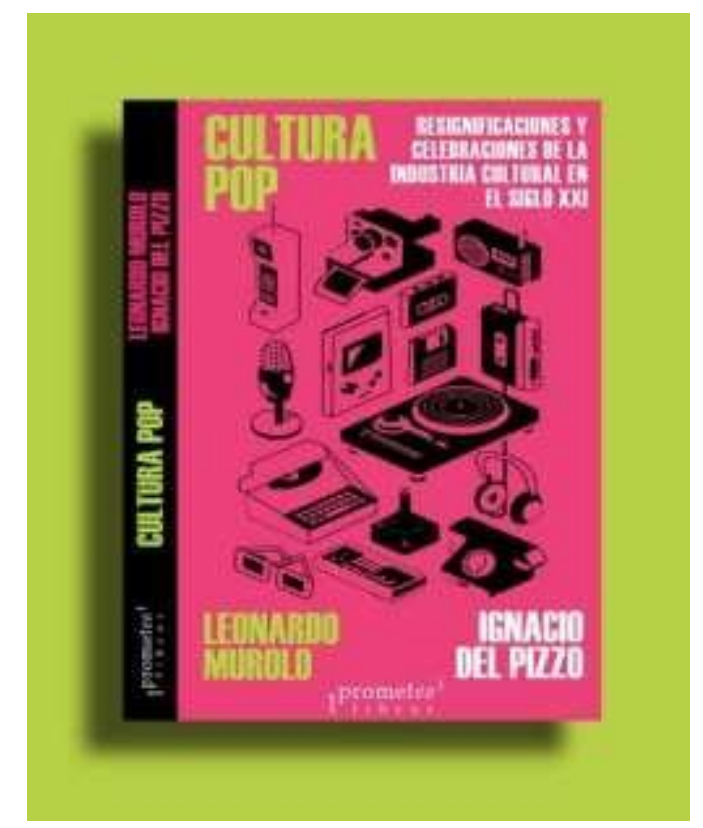

La cantidad de páginas (129) y el índice nos terminan de enamorar. Tanto en tan poco. Ocho grandes temas que se desarrollan de manera fluida, con una escritura ágil y profunda a la vez, y que transitan por las densidades conceptuales de los estudios culturales, de la semiología, la crítica de arte, la teoría crítica entre otras.

La estructura del libro nos presenta un objeto cultural muy cuidado, que significa en cada decisión tomada. Hay un diálogo permanente entre los autores que se lee en las dos secciones (Lado A: el tiempo y Lado B: el espacio), en el contrapunto de los artículos alternados y en equilibrio, y en la confluencia del comienzo y el final en lo que ellos denominan "simple de difusión" y "bonus track".

El producto final es el resultado de un largo proceso gestado al calor de la investigación en la universidad pública, en el marco del proyecto de investigación "Tecnologías, política y cultura popular y masiva. Usos y narrativas de la comunicación en redes" de la Universidad Nacional de Quilmes. También se suman los diálogos en las clases de grado y posgrado y los proyectos de extensión. De esta manera, el libro objetiva a través de un proceso de comunicación pública de la ciencia, múltiples debates, discusiones y reflexiones colectivas que 
nos invitan a pensar sobre las formas de recorrer las nuevas pantallas saberes populares y los nuevos consumos culturales.

\section{Las resignificaciones}

El libro transita cinco puntos nodales:

- La desnaturalización de las prácticas socioculturales

- $\quad$ El anclaje en los sujetos, sus apropiaciones y usos

- $\quad$ La mediación tecnológica de las prácticas

- La dimensión temporal

- $\quad$ La transversalidad de la cultura pop

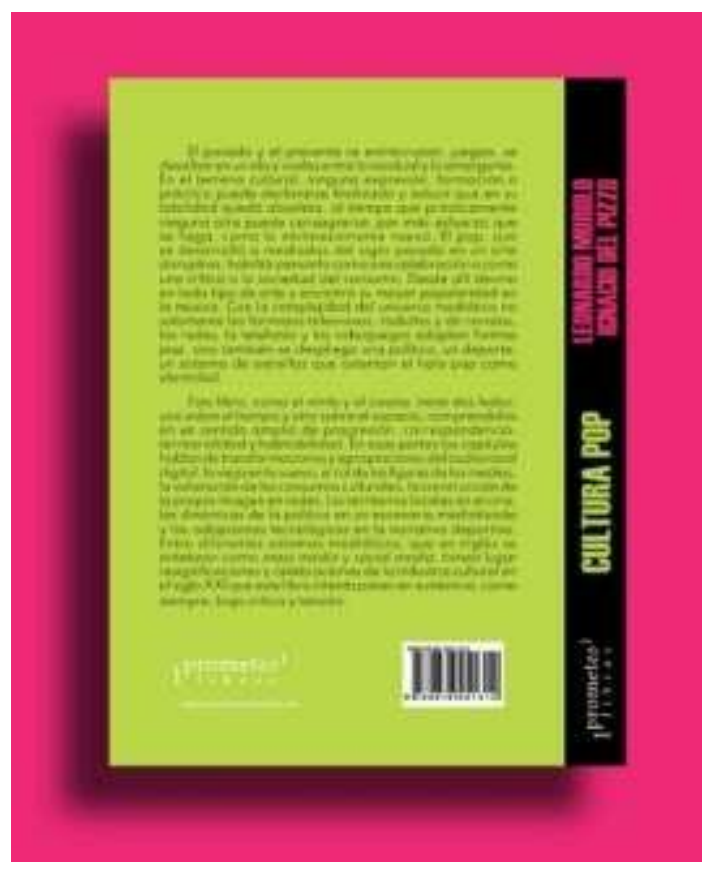


La desnaturalización de las prácticas socioculturales: Los autores se detienen a analizar prácticas habituales, que de tan presentes se convierten en invisibilizadas en la cotidianeidad. La atención puesta en dichas prácticas permite cuestionarlas, historizarlas, ponerlas en relación con otras prácticas. Así emergen las continuidades y rupturas culturales que permiten ver el entramado sobre el cual se sostienen y se legitiman. Este abordaje recupera la tradición de la sociología interpretativa que posa su mirada en pequeños procesos sociales para, a partir de ellos, pensar la sociedad. Es por este motivo que nos encontramos con objetos de estudio que a simple vista parecerían banales, ya que son situaciones, prácticas y vivencias de la vida cotidiana. Pero no nos dejemos tentar por esta aproximación de un juicio a priori. Si hay algo que este libro no es, es ser banal o ser superfluo. Focaliza en prácticas conocidas, pero nos hace mirarlas con otros ojos, con perspectivas conceptuales que las redimensionan y hacen de ellas una mirilla con aumento hacia la profundidad de los sentidos socioculturales.

El anclaje en los sujetos, sus apropiaciones y usos: el lugar de partida de todas las lecturas y análisis realizados por los autores son los sujetos, sus prácticas, sus consumos, los usos de la tecnología que realizan, y la apropiación que hacen de lógicas culturales y la creación de nuevas. Si bien posan sus miradas, como decíamos, en situaciones y objetos conocidos, en realidad analizan las prácticas que se generan desde los procesos subjetivos, identitarios y sociales.

La mediación tecnológica de las prácticas: un lugar convocante son las tecnologías que aparecen asociadas a las experiencias socioculturales narradas. Como signo de una época, la tecnología nos atraviesa en nuestro modo de ver el mundo y actuar en él. Sin embargo, los autores deciden recuperar estas lecturas para ir hacia los sujetos. Lejos está este libro de hablarnos sobre determinismos tecnológicos, mas bien nos proponen pensar las mediaciones y los sentidos asignados.

La dimensión temporal: un lugar clave en esta trama analítica lo constituye la perspectiva temporal que atraviesa todos los artículos. Los autores reconstruyen a través de una mirada histórica, los modos culturales de vivir y significar ciertos hechos que aparecen recuperando continuidades entre el pasado y el presente. Asimismo, a partir de la idea de nostalgia, entrelazan un andamiaje interpretativo que posibilita desnudar ciertas apropiaciones 
culturales nodales para comprender nuestro presente donde lo obsoleto y lo nuevo parecen desdibujarse.

Por último, la transversalidad de la cultura pop: si hay algo que podemos afirmar, es que la cultura pop nos constituye mucho más de lo que suponemos. Por ello, es necesario el análisis de las industrias culturales. El libro lo logra visitando y revisitando los memes, los esports, las series, las prácticas de maratonear o spoilear, los territorios del cine, las selfies, la política y los tweets, entre otras entradas que nos permiten mirar y mirarnos. Esta heterogeneidad nos posibilita reconocernos en alguno de todos estos temas, o en todos. Lo que seguro no nos sucede es quedarnos afuera, porque la cultura pop está aquí, entre nosotros, atravesándonos.

\section{La celebración}

La lectura se transita de manera muy ágil entre una variedad de objetos y situaciones, a través de una narrativa crítica y abierta. Nos instala la pregunta y nos deja un listado enorme de transferencias posibles a otras prácticas, otros usos, otras significaciones. Por eso no termina: abre un modo de ver y analizar la cultura del SXXI.

Todo lo que el libro promete, lo cumple. Por eso esta reseña es una nueva invitación, esta vez a dejarse invitar por el libro. Transiten, recorran, lean. Después de ello, no podrán borrar la sonrisa de sus caras, vivenciando, analizando, resignificando y celebrando la cultura pop.

\section{Los autores}




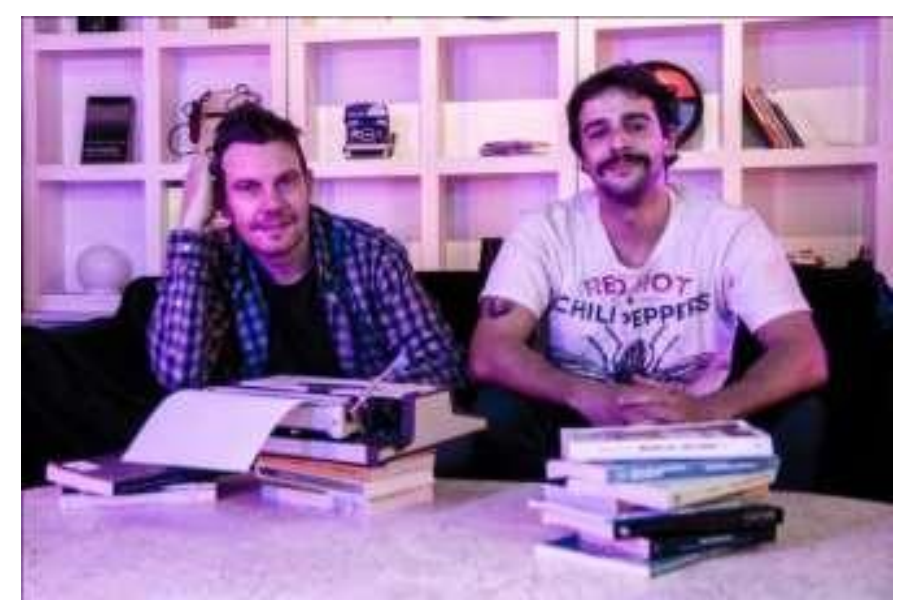

Leonardo Murolo es Doctor en Comunicación por la Universidad Nacional de La Plata. Profesor, investigador y director de la Licenciatura en Comunicación Social en la Universidad Nacional de Quilmes.

Ignacio Del Pizzo es Maestrando y Especialista en Comunicación Digital Audiovisual, Licenciado en Comunicación Social y Diplomado en Ciencias Sociales por la Universidad Nacional de Quilmes, donde se desempeña como docente, investigador y extensionista. 